\title{
Actitudes sefardíes del siglo XIX y pensamiento sansimoniano reflejados en las carreras de Emile e Isaac Péreire, fundadores del Crédit Mobilier
}

Michael ALPERT

Universidad de Westminster, Londres

\section{BURDEOS, REFUGIO DE CRISTIANOS NUEVOS}

Los judíos portugueses de Burdeos de principios del siglo XIX eran descendientes de aquellos cristianos nuevos que durante siglos habían vivido en la Península Ibérica como católicos, pero observando a la vez, en la medida de lo posible y a hurtadillas de la Inquisición, las normas del judaísmo.

Impulsados por sucesivos acontecimientos, como el establecimiento de la Inquisición en España en 1478, la expulsión de los judíos en 1492, su conversión obligatoria en Portugal en 1497 y la aparición de la Inquisición en Portugal en 1536, proceso que concluye en la segunda mitad del siglo XVIII cuando el Santo Oficio deja de interesarse por los herejes judaizantes, unas cuantas decenas de miles de judíos y conversos abandonaron España y Portugal para buscar refugio en otros lugares: primero en Italia y Turquía; luego en Bayona, Burdeos, Ruán, Amsterdam, Liorna, Hamburgo y Londres; y más tarde en las Indias inglesas y holandesas.

En cuanto a Francia, la población de cristianos nuevos de Burdeos venía creciendo desde la segunda mitad del siglo XVII. Los «marchands portugais nouveaux-chrétiens» contribuyeron a acre- 
centar la riqueza de la gran ciudad portuaria construyendo barcos para las rutas comerciales del Atlántico y a la vez invirtiendo ampliamente en la industria y en el comercio.

Entre otros, Abraham Gradis (1699-1780), junto con David Lindo, Abraham Francia y Gabriel da Silva, exportaron carnes, vinos y harina a las Indias Occidentales, e importaron azúcar ${ }^{1}$.

En la primera mitad del siglo XVIII un redoblado ataque contra los criptojudíos por parte de las inquisiciones peninsulares estimuló la salida de cristianos nuevos ${ }^{2}$. Las autoridades francesas, sin embargo, iban aceptando que los portugueses oficialmente católicos eran judíos observantes.

Un informe del Intendente real francés, fechado el 7 de febrero de 1734 , menciona la presencia en Burdeos de rabinos que presidían bodas judías. Además, el Intendente informaba de que las tiendas de los mercaderes portugueses se cerraban los sábados, los judíos celebraban sus fiestas y días santos, y en 1711 habían establecido una sinagoga. Llevaban abiertamente el sisit y tocaban el šofar en el mes que precede a los días del Año Nuevo ${ }^{3}$ y ya no hacían bautizar a sus hijos ni acudían a sacerdotes católicos para santificar sus matrimonios.

Pese a que los portugueses eran judíos, los intendentes de Burdeos presionaron al rey para que a los sefardíes no se les tratara como a los humildes asquenasíes de Alsacia y Lorena, los cuales vivían con poca seguridad personal, sufriendo la imposición de

1 Para la familia Gradis véase R. MENKIS, «Patriarchs and Patricians: The Gradis Family of Eighteenth Century Bordeaux», en F. MALINO y D. SORKIN (eds.), From East to West: Jews in a Changing Europe 1750-1870 (Oxford: Blackwell, 1990) págs. 11-46; sobre los intereses comerciales vid. especialmente pág. 18. Vid. también el estudio de G. NAHON, «The Sephardim of France», en R. BARnETT y W. SCHWAB (eds.), The Sephardi Heritage, vol. II: The Western Sephardim (Grendon: Gibraltar Books, 1989) págs. 46-74, con abundantes referencias.

2 Para una descripción de la campaña contra los cristianos nuevos observantes del judaísmo en el siglo XVIII consúltese M. ALPERT, «The Secret Jews of Eighteenth Century Madrid», Revue des Études Juives 156/1-2 (en.-jun. 1997) págs. 135-171.

3 Informe de Jean Pudeffer dirigido al Intendente de la Guyenne, publicado en S. SCHWARZFuCHS (ed.), Régistre des déliberations de la Nation juive portugaise de Bordeaux 1711-1787 (París: Fundação Calouste Gulbenkian e Centro Cultural Português, 1981) Anejo 2. Vid. también F. MALino, The Sephardic Jews of Bordeaux: Assimilation and Emancipation in Revolutionary and Napoleonic France (Tuscaloosa: University of Alabama Press, 1978) pág. 22. 
contribuciones onerosas. A su vez, los jefes de la Nação Portuguesa, como se llamaban los judíos portugueses de Burdeos y Bayona, controlaban estrechamente su comunidad, en parte para salvaguardar sus relaciones con las autoridades francesas ${ }^{4}$.

Uno de los criptojudíos que llegaron a Francia en esta época fue Jacob Rodrigues Pereira (1715-1780), abuelo de Emile e Isaac Péreire. Arribó a Burdeos en 1734 a la edad de diecinueve años, después de que el Santo Oficio condenara a su madre a realizar una humillante abjuración pública de su judaísmo ${ }^{5}$. La Académie des Sciences reconoció en 1745 el prestigio de Rodrigues Pereira, el cual había inventado un método para la enseñanza de los niños sordomudos, premiándole con una pensión de 800 francos anuales. En junio de 1776, Rodrigues Pereira, que ya gozaba de amplia influencia en Francia, obtuvo una patente que dio a los judíos bordeleses privilegios muy superiores a los de Alsacia e incluso a los que vivían en los ex-territorios papales de Avignon y Carpentras, privilegios que los sefardíes insistirían en preservar en épocas posteriores.

\section{CAMBios REVOLUCIONARIOS}

Durante los debates sobre cómo tratar a los judíos que empezaron en 1787, fecha de la concesión de derechos civiles a los protestantes franceses, y en el curso de los siguientes veinte años -época de la Revolución y del Imperio napoleónico-, los sefardíes de Burdeos hicieron hincapié en su deseo de vivir como cualquier otro francés, aceptando las restricciones oportunas sobre la práctica religiosa si en algo entraba en conflicto el judaísmo con sus obligaciones como ciudadanos. Sin embargo, se oponían a perder la autonomía por medio de la cual los portugueses se definían como diferentes y hasta superiores a los otros judíos que vivían en Francia.

En junio de 1788 dos miembros de la comunidad de judíos portugueses de Burdeos, Salomón Lopès-Dubec y Abraham Furtado,

\footnotetext{
${ }^{4}$ Ver Malino Sephardic, y también las obras de T. MALvezin, Histoire des Juifs à Bordeaux (Bordeaux: Lefebvre, 1875), y H. LÉON, Histoire des Juifs à Bayonne (París: Durlacher, 1893). Véase también Z. SJAIKOWSKI, «Population problems of Marranos and Sephardim in France from the 16th to the 20th Centuries», en Z. SJAIKOWSKI (ed.), Jews and the French Revolutions of 1789, 1830 and 1838 (Nueva York: Ktav, 1970) págs. 1-23.

5 J. Autin, Les Frères Péreire (París: Perrin, 1984) pág. 15.
} 
y otro de Bayona, representando a las dos comunidades ex-peninsulares, presentaron al Gobierno un documento en el cual hacían resaltar las diferencias entre ellos y otros judíos ${ }^{6}$. Declaraban que los sefardíes se incorporarían enteramente a la sociedad francesa una vez que esta les reconociera como ciudadanos con iguales derechos a los demás.

Los portugueses presionaron a los delegados de la Asamblea Nacional para que reconocieran que los judíos tenían derecho a ocupar cargos públicos. El 28 de enero de 1790 consiguieron que la Asamblea decretara que los judíos portugueses y aviñoneses seguirían gozando de los derechos de los que habían disfrutado hasta aquel momento ${ }^{7}$. En contrapartida, sin embargo, la Asamblea exigió que la Nation Portugaise se disolviera como cuerpo, lo cual hizo la comunidad de Burdeos el 18 de febrero de 1790 .

El 27 de septiembre de 1791 se concedió la igualdad total de derechos a todos los judíos de Francia. Los portugeses de Burdeos tomaron parte activa en la comuna de su ciudad, alistándose en el ejército revolucionario o en la Guardia Nacional. En Saint Esprit, barrio portugués-judío de Bayona, el Comité de Salud Pública estaba compuesto principalmente de judíos, los cuales, emborrachados por el ambiente antirreligoso, llegaron incluso a cerrar algunas sinagogas y prohibieron la observancia del sábado ${ }^{8}$.

\section{NAPOlEÓn Bonaparte y los PORTUGUESES DE BuRdeOS}

Antes de imponer una organización comunitaria judía -los consistoires - controlada por el Estado, Napoleón Bonaparte convocó en julio de 1806 una asamblea de «notables» judíos, presidida por el bordelés Abraham Furtado, para que contestaran a las preguntas del Emperador sobre la legislación judía en materias de matrimonio y divorcio, y sobre la devoción patriótica de los judíos por Francia.

${ }^{6}$ Malino Sephardic págs. 19, 25 y 27-28. Véase allí la Memoria de Furtado y Lopès-Dubec dirigida a Malesherbes, ministro real que se ocupaba de cuestiones judías.

${ }^{7}$ Sobre los judíos de Avignon, Carpentras y otras poblaciones del Comtat Venaissin durante la Revolución, consúltese M. CALmann, The Carrière of Carpentras (Oxford: Oxford University Press for Littman Library, 1984) cap. 10.

${ }^{8}$ LÉON Histoire págs. 165-166. 
Los diputados que participaron en la Asamblea de Notables ambicionaban hacer compatible la vida judía con las exigencias de la ciudadanía francesa. Los debates, sin embargo, subrayaron la profunda diferencia que existía entre los sefardíes y los asquenasíes. Aquellos se resistían, aun a riesgo de su judaísmo, a comprometer sus obligaciones con Francia, mientras estos se obstinaban en no sacrificar la más mínima parte de su práctica religiosa.

Cuando entre el 9 de febrero y el 9 de marzo de 1807 Napoleón convocó el llamado «Sanhedrín» con el fin de establecer las decisiones de la Asamblea de Notables como si fuesen artículos de un código rabínico, el portugués Abraham Furtado llevaba la voz cantante, insistiendo que el Sanedrín no haría más de lo que le permitía el judaísmo, es decir, legislar para una situación fundamentalmente nueva. Furtado representaba el punto de vista de los sefardíes de Burdeos, los cuales no tenían mayor interés en defender unos sentimientos culturales específicamente judíos si estos entraban en conflicto con los que el mismo espíritu del Siglo de las Luces prescribía.

Como escribe un autor,

In setting forth the separation of belief and ritual from daily life, the dissolution of nationhood and the reinterpretation of the messianic dream ... the doctrinal decisions [of this Sanhedrin] provided a definitive formula and an enduring rationale for a profound break with Jewish tradition ${ }^{9}$.

Los sefardíes pedían una consideración excepcional debido a su superioridad autopercibida y a los privilegios de los que ya disfrutaban. Los sefardíes de Burdeos -y gracias a los esfuerzos de Furtado unos catorce mil judíos más de París, de Provenza y de los departamentos de habla italiana- se vieron exentos de unos decretos imperiales que anulaban muchas de las deudas pendientes debidas a los judíos.

Cuando el 12 de diciembre de 1809 le fue presentado a Napoleón el recién nombrado Consistoire Central judío, el Emperador le preguntó a uno de los vocales, el joyero parisino Jacob Lazard, si el consistorio efectuaría la corrección de las costumbres judías insatisfactorias. «Todos merecerán dentro de poco ser súbditos de

${ }^{9}$ Malino Sephardic págs. 94-99. 
Vuestra Majestad», contestó el joyero. «Bueno», dijo Napoleón, «Haced como los judíos de Burdeos, como los portugueses» ${ }^{10}$.

El consistorio bordelés, comunidad de 3.713 judíos, se creó el 10 de mayo de 1809 y la nueva sinagoga se inauguró el 14 de mayo de $1812^{11}$.

\section{LOS PÉREIRE Y EL LEGADO SEFARDí}

Tales sucesos tuvieron lugar durante la infancia de los hermanos Péreire. Por otra parte, Emile (n. 1800) e Isaac (n. 1806), nietos de Jacob Rodrigues Pereira, eran también herederos de unas actitudes y tradiciones diferentes no sólo de los cristianos sino también de otros judíos, tradiciones con profundas raíces históricas que se verían reforzadas por el espíritu de la edad en la que vivieron.

Los judíos portugueses de Burdeos descendían de los criptojudíos que habían vivido durante muchas generaciones en la Península, preservando su conciencia judía y unas cuantas prácticas religiosas en un ambiente peligroso, amenazados siempre con ser descubiertos, arrestados, interrogados e incluso, hasta mediados del siglo XVIII, de morir en la hoguera.

Separados de otras comunidades judías, su judaísmo se hallaba fuertemente influido por el modo cristiano de vida que tuvieron que fingir. Profesaban una religión exterior falsa mientras que su verdadera fe la guardaban intensamente en su interior. Por consiguiente, los preceptos religiosos que no habían podido cumplir en la Península Ibérica perdieron importancia para ellos.

Esa actitud hacia los detalles de la ley judía caracterizaba a muchos de los miembros de las comunidades ex-ibéricas de la Europa occidental, mal preparadas para observar el judaísmo rabínico del cual habían estado completamente aisladas. Al llegar a una comunidad judía libre, especialmente la muy importante de Amsterdam, los huídos de la Inquisición encontraban un universo de discurso judío extraño para ellos, por lo cual a menudo lo rechazaban ${ }^{12}$.

\footnotetext{
10 SChWARZFUCHS Régistre pág. 141.

11 MALvezin Histoire pág. 303.

12 Para una descripción de cómo ese conflicto se planteó en Londres, vid. J. PetUChOvSKI, The Theology of Haham David Nieto (1954; reed. Nueva York: Ktav, 1970) págs. 12-13, 33-35, 40 y 46. Vid. también G. SHOLEM, Major Trends in
} 
El encuentro con el judaísmo normativo y su rígido código legal inclinaba a algunos de los recién llegados a aplicar sus intelectos críticos al judaísmo, descartando el concepto mismo de una religión revelada para adherirse a la teología mínima del deísmo ${ }^{13}$.

Semejantes ideas, descritas por un autor como «mezcla extraña de fundamentalismo, negación del cristianismo y un monoteísmo cristianizado» ${ }^{14}$, estaban presentes en la comunidad de Burdeos. Además, en esa ciudad la autoridad rabínica, los estudios talmúdicos y los conocimientos del judaísmo se encontraban en un bajo nivel ${ }^{15}$.

\section{LA VISITA DEL RABINO AZULAY}

Fuente principal para nuestros conocimientos de la comunidad bordelesa de esta época es el dietario titulado Séfer Máágal tob del rabino de Hebrón Haim Yosef David Azulay, el cual visitó Burdeos en 1755 y de nuevo en $1777^{16}$.

Durante su primera visita el rabino recelaba mucho de la corrección del sacrificio kašer de las reses, pero subraya que se abstuvo de criticarla para no rebajar aun más el prestigio del rabino de la comunidad, Jacob Attías. En su segunda visita Azulay tuvo ciertas diferencias con los jefes de la comunidad, los cuales rechazaban algunas de las tradiciones de la legislación rabínica. Del

Jewish Mysticism (Nueva York: Shocken, 1961, ed. de bolsillo) págs. 307-309. Véanse también dos biografías intelectuales y espirituales de ex-cristianos nuevos: Y. KAPLAN, From Christianity to Judaism: The Story of Isaac Orobio de Castro, trad. del hebreo R. LOEWE (Oxford: Oxford University Press for Littman Library, 1989); y Y. H. Yerushalmi, From Spanish Court to Italian Ghetto: Isaac Cardoso, a Study in Seventeenth Century Marranism and Jewish Apologetics (Nueva York: Columbia University Press, 1971; trad. española de M. y A. CEREZALES, De la corte española al gueto italiano: marranismo y judaísmo en la España del siglo XVII [Madrid: Turner, 1989]). Para un estudio profundo de la cuestión vid. G. AlBIAC, La sinagoga vacía: Un estudio de las fuentes marranas del espinosismo (Madrid: Hyperión, 1987).

13 PETUChowsKi The Theology págs. 35 y 40; KAPLAN From Christianity págs. 132-133, 135 y 140-141. Véase también Y. KAPLAN, Judios nuevos en Amsterdam (Barcelona: Gedisa, 1996) esp. pág. 19.

${ }_{14}$ T. Oelman, Marrano Poets of the Seventeenth Century (Londres: Associated University Presses, 1982) pág. 32.

15 SChwarzfuchs Régistre págs. 8 y 24; Malino Sephardic pág. 24.

${ }^{16}$ Las referencias de Azulay a Burdeos las recoge SCHWARTZFUCHS Régistre Anejo 2 (en francés). Hay una edición comentada en inglés, The Diaries of Rabbi Ha'im Yosef David Azulai, trad. y com. de B. CYMERMAN (Jerusalén: Bnei Issakhar Institute, Otsrot Hamagreb, 1997). 
presidente comunitario, Salamón Lopès, escribió Azulay: «no cree en nuestros rabinos y se considera un filósofo» ${ }^{17}$.

La enseñanza de los niños de la comunidad mereció también las críticas del rabino de Hebrón. «Desgraciadamente», escribe, «en este Talmud Torá estudian sólamente Biblia», con lo que quería decir que hacían caso omiso de Raší, el comentarista medieval de las Escrituras más conocido, «porque contiene midrašim», es decir, explicaciones no basadas en el sentido literal del texto ${ }^{18}$.

Azulay habla en términos duros de una persona importante, a quien trata de «apóstata y profanador en público del sábado» ${ }^{19}$; y de Abraham Gradis, persona honrada en el Corte Real, millonario y filántropo, dice que es «gran apóstata, que come en público alimentos prohibidos» ${ }^{20}$.

La dureza de las observaciones hechas por el rabino Azulay en su segunda visita a Burdeos es notable. Para esta segunda mitad del siglo la autoridad laica se había apoderado firmemente del sistema educativo. En su testamento Abraham Gradis legó importantes sumas para financiar la enseñanza de asignaturas laicas en las escuelas de la comunidad sefardí de Burdeos, fundadas en 1766 para enseñar la gramática hebrea, la Biblia en castellano y la liturgia. En una junta celebrada en 1773 bajo la presidencia del sobrino de Gradis, se había instituido un nuevo programa de estudios. La Biblia se enseñaría en adelante solamente con los comentarios de los mejores gramáticos -es de suponer que los sefardíes Ibn 'Ezrá y Quimhí-, y como notó el rabino Azulay, la exégesis enseñada sería la literal y no la basada en el midrás ${ }^{21}$.

El sistema educativo parece notablemente moderno. No se admitían los castigos físicos y sin embargo se mantenía la disciplina ${ }^{22}$. La enseñanza judía de la comunidad sefardí bordelesa debía ajustarse a los ideales del Siglo de las Luces y a la elegancia de la tradición sefardí.

En efecto, el sobrino de Abraham, David Gradis (m. 1810), escribió textos en los que declaró no creer en la creatio ex nihilo a la

17 Ed. CYMERMAN The Diaries pág. 170. Azulay acusa a Lopès de haber engendrado ocho hijos sin que su mujer hubiera hecho la inmersión mensual prescrita.

18 Ed. CYMERMan The Diaries pág. 171.

19 Ed. CYMERMAN The Diaries pág. 174; se trata de Jacob Azevedo y sus hijos.

20 Ed. CYMERMAN The Diaries pág. 174.

21 Véase MENKIS «Patriarchs»; vid. también Malino Sephardic pág. 25.

22 SCHWARZFuCHS Régistre pág. 44. 
vez que proclamaba su intención de rescatar la Biblia de lo que consideraba la falsa interpretación rabínica. En 1806, año en que nació Isaac Péreire, Gradis habló en público contra el Talmud. Un judío necesitaba, dijo, nada más que una traducción literal de la Biblia y su propio sentido común, mientras que la obligación de la filosofía era la de acercar al hombre a Dios, considerado como la primera causa aristotélica ${ }^{23}$.

Puede suponerse, por tanto, que la formación religiosa recibida por los hermanos Péreire a principios del siglo XIX era aún menos rigurosa que la impartida antes de la Revolución, cuando el programa se había limitado a la gramática hebrea, los Salmos de David y los libros proféticos, es decir, los textos éticos e inspiradores más que las secciones legales de las Escrituras. Resulta notable la ausencia de los estudios rabínicos que dominaban la enseñanza asquenasí.

En Burdeos se hacía hincapié en las tradiciones sefardíes de orden y decoro. Tal visión del judaísmo se asociaba fácilmente con el racionalismo del Siglo de las Luces. Incluso se podía decir que ese tipo de formación judía se limitaba a aquellos aspectos del judaísmo más compatibles con una forma menos dogmática de cristianismo. Efectivamente, el reflejo del pensamiento de la Ilustración favorecía una religión «natural» y «razonable», tal como podía ser el deísmo, de aplicabilidad universal y cuyos principios incluían la existencia de Dios, el deber humano de adorarlo y la necesidad de la piedad y de la virtud.

Entre aquellos judíos que aceptaban los ideales de la Ilustración el deísmo se plasmaba en el rechazo del rabinismo -la regulación de la vida diaria- mientras que para los cristianos aceptar las ideas deístas sugería el final del judaísmo y hasta la fusión del judaísmo y del cristianismo en una nueva síntesis superior ${ }^{24}$.

En 1787 el conde de Mirabeau, en su obra que defendía la concesión de derechos civiles a los judíos, escribía:

Il n'y a pour toutes les âmes qu'une même raison, et la morale universelle des peuples et des souverains, fondée sur la nature et sur l'ordre universel, ne peut changer ${ }^{25}$.

${ }_{23}$ A. Herzberg, The French Enlightenment and the Jews (Nueva York: Columbia University Press, 1968) págs. 158-159.

${ }^{24}$ La relación entre las ideas religiosas del siglo XVIII y el movimiento reformista judío del XIX se halla descrito en M. MEYER, Response to Modernity: A History of the Reform Movement in Judaism (Oxford: Oxford University Press, 1988) pág. 7. Vid. también PeTUCHOVSKI The Theology págs. 11-12.

${ }^{25}$ Mirabeau, Sur la réforme politique des Juifs (Londres 1787) pág. 61. 
En efecto, uno de los primeros judíos que abogó por una religión universal fue el sefardí Joseph Salvador (1796-1873), al cual los hermanos Péreire admiraban. En sus obras Loi de Moïse (1822) y la muy posterior Paris, Rome, Jérusalem (1860), Salvador describía la ley mosaica como el paradigma del Estado ideal, por lo cual proponía que se la adoptara como solución universal y mesiánica a la cuestión judía y al papel general de la religión en la sociedad ${ }^{26}$.

\section{LOS HERMANOS PÉREIRE Y EL SANSIMONIANISMO}

Emile Péreire, el mayor de los hermanos, trabajó primero como empleado de un agente inmobiliario, mientras Isaac prestó sus servicios en la casa exportadora de los Gradis. Poco tiempo después el deseo de medrar llevó a ambos a París, donde se alojaron con su tío Isaac Rodrigues, empleado del banco Fould ${ }^{27}$. En la capital francesa Emile se colocó en la Bolsa, mientras que Isaac ascendió rápidamente, ocupando el cargo de contador mayor en el banco Vital-Roux ${ }^{28}$.

El escritor Emile Feydeau compuso una descripción a menudo citada acerca de la llegada a la Bolsa parisina de un grupo de jóvenes judíos bordeleses:

Bordeaux fut, de tout temps, la grande pépinière qui alimenta la Bourse del fils d'Israël. Ils arrivent de là-bas, tout jeunes, tout petits, presqu'encore enfants; ils trouvent tout de suite à se placer chez l'un de leurs correligionnaires en qualité de commis; on leur achète un carnet de dix sous, un crayon de quinze centimes; et tout de suite, sans avoir fait d'apprentissage préalable, sans autre raison d'être que leur qualité de Juifs, par la seule force de leur sang, ils se lancent dans le groupe, le bras levé, et se mettent à vociférer dans leur atroce baragouin méridionale, abattent des affaires, même des plus grosses, comme s'ils n'avaient fait que cela toute leur vie ${ }^{29}$.

26 Vid. P. HYMAN, «Joseph Salvador: Protagonist or Apologist for Assimilation», Jewish Social Studies 34 (1972) págs. 1-22.

27 Autin Les Frères Péreire pág. 22.

${ }_{28}$ R. CAmeron, France and the Economic Development of Europe (Princeton: Princeton University Press, 1967) pág. 114 nota 19.

${ }^{29}$ E. FEYDEAU, Mémoires d un coulissier (París: Librairie Nouvelle, 1873) págs. $165-166$. 
Descartando la evidente malevolencia del autor de esta cita, lo que pone de relieve es que un pequeño número de judíos de provincias irrumpió en el mundo tranquilo de la Bolsa parisina, dando la impresión de poseer una capacidad natural -Feydeau la interpreta como habilidad racial heredada- para manejar sus complicaciones y, por consiguiente, para prosperar.

Aquella época no ofrecía mucho porvenir a judíos jóvenes y capaces; además los autores antijudíos recomendaban el ostracismo social ${ }^{30}$. Los Péreire y sus contemporáneos, abogados de la reforma y del progreso, que veían el judaísmo desde su ángulo individual bordelés, rechazaban el bautismo cristiano buscando un programa donde poder expresar la visión ética fundamentalmente judía que habían aprendido desde niños, según la cual el trabajo expresaba un ideal religioso a la vez que la riqueza producida por tal trabajo debía de canalizarse en beneficio de todos ${ }^{31}$.

Los Péreire encontraron apoyo intelectual y emocional en las doctrinas del conde Claude-Henri de Rouvroy de Saint Simon (1760-1825) a las que les introdujeron sus primos Benjamin Olinde Rodrigues y Eugène Rodrigues.

Para Saint-Simon la finalidad de la historia la constituía la construcción de una sociedad industrializada, dirigida por una élite científica y basada en el repartimiento de funciones según las capacidades de cada cual ${ }^{32}$. Saint-Simon creía que la religión, ayudada por la ciencia y por la aplicación tecnológica, mejoraría las condiciones sociales. El «cristianismo nuevo» sansimoniano se dirigía a todo judío o cristiano que considerara la moralidad como el objetivo fundamental de la religión. El sansimonianismo criticaba tanto al cristianismo histórico por haber dejado de cumplir las enseñanzas de Jesús como al actual que se apoyaba en exceso en el dogmatismo y en el ritualismo. Ni el papado ni la jerarquía de la Iglesia observaban la base moral del cristianismo. Para los sansimonianos, el cristianismo primitivo, ayudado por el judaísmo

${ }^{30}$ J. Berkovitz, The Shaping of Jewish Identity in Nineteenth Century France (Detroit: Wayne State University Press, 1989) pág. 113.

31 Berkovitz The Shaping págs. 114-115.

32 Vid. G. IONESCU (ed.), The Political Thought of Saint-Simon (Oxford: Oxford University Press, 1976) págs. 204ss. Véase también Robert B. CARLisle, The Proffered Crown: Saint-Simonianism and the Doctrine of Hope (Baltimore: The Johns Hopkins University Press, 1987) con diversas referencias a los Péreire. 
bíblico y una nueva religión universal, constituía el criterio que debería guiar la acción del poder temporal.

En el concepto sansimoniano los científicos disfrutaban de un papel excepcional: elite sin relación con la estructura social existente, deberían situarse en el ápice de la sociedad como un sacerdocio universal. Esos sacerdotes-científicos resolverían la crisis moral de la humanidad; los cerebros más dotados dedicarían sus capacidades a lograr la paz y felicidad sociales, cuestionando los supuestos actuales en busca de síntesis cada vez más avanzadas.

El jefe ideal poseería en igual medida las tres capacidades que caracterizaban al género humano: la emocional, la racional y la impulsora. Las personas más dotadas de esta última capacidad serían los gerentes y los tecnólogos, que aplicarían los descubrimientos de los científicos racionales. La nueva tecnología del siglo, en vez de servir sólo para enriquecer al capitalista, beneficiaría a la humanidad entera. La sociedad se fundamentaría en el principio de la cooperación; nadie sería explotado y la naturaleza sería dominada por la ciencia y la aplicación de la tecnología. La productividad resultante incrementaría el bienestar físico y moral de todos, y de este modo el capitalismo filantrópico lograría el progreso universal.

Tales doctrinas atraían a jóvenes judíos de inclinación científica, tecnológica o financiera, muchos de los cuales se hallaban alejados de la práctica religiosa y a la vez imposibilitados de entrar con plenos derechos en el mundo cristiano. Por otra parte, la visión sansimoniana de un progreso basado en la inversión tecnológica no estaba reñida con los conceptos judíos, pero sí entraba en conflicto con opiniones cristianas anti-capitalistas y como tal sería atacada por autores antijudíos.

El sansimonianismo poseía una dimensión moral muy clara, ya que preveía el final del antagonismo entre las clases sociales y el auge del asociacionismo y del mutualismo. Esos ideales universales y utópicos del sansimonianismo atraían a los jóvenes de la primera generación de judíos que gozaban de derechos civiles y también satisfacían hasta cierto punto las exigencias espirituales de aquellos que ya no se sentían completamente unidos a las comunidades de las que eran oriundos ${ }^{33}$.

33 Vid. Barrie M. RATCLiffe, «Some Jewish Problems in the Early Careers of Emile and Isaac Péreire», Jewish Social Studies 34 (1972) págs. 189-207. 
Después de la muerte de Saint-Simon, acaecida en 1825, sus discípulos convirtieron su sistema en un culto intelectual y -en el ala extremista del sansimonianismo- religioso. El sansimoniano más destacado era Benjamin Olinde Rodrigues (1795-1851), primo de los Péreire, cuya ambición le llevó al mundo de la banca, donde dirigió la Caisse Hypothécaire, empresa pionera en la extensión del empleo del crédito.

En sus escritos teóricos Rodrigues propuso el reparto de beneficios entre el personal de las empresas además de gravar el capital inmóvil. Inventó también un fondo mutual para ofrecer derechos pasivos a los jubilados ${ }^{34}$. No faltaba la visión neo-religiosa; en el prefacio que Rodrigues compuso para la edición de 1832 de las obras de Saint-Simon escribió que el sansimonianismo sería la «reunión de los judíos y los cristianos en el seno de un cristianismo nuevo, una religión universal» ${ }^{35}$.

Para los matemáticos, ingenieros y hombres poseedores de imaginación financiera, tales como los Rodrigues y los Péreire, las doctrinas industriales de Saint-Simon reflejaban los valores judíos. El sansimonianismo era el capitalismo y la empresa atemperados por la responsabilidad social ${ }^{36}$. Durante toda su vida Emile e Isaac Péreire insistieron en que el papel de las finanzas era el de mejorar la suerte de los ciudadanos más pobres y más numerosos de un país ${ }^{37}$.

El 16 de septiembre de 1831, en la primera de cuatro «lecciones» publicadas en Le Globe, órgano de los sansimonianos, Emile Péreire escribió que la principal finalidad de un sistema monetario y crediticio debía ser «la décroissance successive de l'oisiveté, le progrès vers l'association universelle des travailleurs».

Para judíos tales como los Rodrigues y los Péreire, los cuales habían rechazado el bautismo, el «nuevo cristianismo» sansimoniano ofrecía un ideal de sincretismo religioso y moral, apoyado en el espírito científico y empresarial. A la vez, estos jóvenes educados en los ideales de la comunidad sefardí bordelesa rechazaban toda sugerencia de una depreciación de los valores judíos. En efecto,

34 Vid. Carlisle The Proffered Crown pág. 212.

35 Vid. J. L. Talmon, Political Messianism: The Romantic Phase (Londres: Secker and Warburg, 1960) pág. 79; también G. WEILL, «Les Juifs et le SaintSimonisme», Revue des Études Juives 33 (1895) págs. 261-273.

36 J. L. TALMON, «Social Prophetism in Nineteenth Century France: The Jewish Element in the Saint-Simonian Movement», Commentary 26 (1958) págs. 158-172.

37 F. MAnuel, The Prophets of Paris (Cambridge: Harvard University Press, 1962) pág. 191. 
Benjamin Olinde Rodrigues insistía en que era su judaísmo el que le había comunicado su respeto instintivo hacia la clase obrera ${ }^{38}$.

Estar afiliado a un movimiento utópico asociacionista constituía un modo de transcender los límites particularistas del judaísmo, una forma de redencionismo laico que correspondía al tradicional mesianismo judío pero sin la presencia de un mesías personal. En la introducción que compuso a su traducción francesa de las Cartas sobre la Ilustración de la Humanidad de Lessing, Eugène Rodrigues exigió la creación de una síntesis religiosa que sanctificara el progreso por el esfuerzo constructivo y la justicia social ${ }^{39}$. El mismo Saint-Simon había reconocido que eran los judíos los que primero habían vislumbrado una nueva edad, al escribir:

Le peuple de Dieu, celui qui avait reçu des révélations avant l'apparition de Jésus, celui qui est le plus généralement répandu sur toute la surface du globe, a toujours senti que la doctrine chrétienne, fondée par les Pères de l'Eglise, était incomplète; il a toujours proclamé qu'il arriverait une grande époque, à laquelle il a donné le nom de messianique, époque où la doctrine religieuse serait présentée avec toute la généralité dont elle est susceptible, qu'elle réglerait également l'action du pouvoir temporel et celle du pouvoir spirituel et qu'alors toute l'espèce humaine n'aurait plus qu'une seule religion, qu'une même organization ${ }^{40}$.

No es totalmente casual que los hermanos Rodrigues y sus primos, Emile e Isaac Péreire, proviniesen de un mundo que se había encontrado en los márgenes de la sociedad judía debido a su historia secreta y a su rechazo del particularismo y del rabinismo. El sansimonianismo ofreció a los Péreire un vehículo y un estímulo para proclamar que el mesianismo ya no era particularista sino universal, científico y secularizado, incluso de orden socialista y no específicamente judío. El mesianismo podría ser traducido ahora en una filosofía de la historia y un concepto moderno de la sociedad en la que desaparecerían las diferencias raciales y religiosas.

Como escribía Joseph Salvador, tan admirado por los Péreire, en su Histoire des Institutions de Moïse (1828):

${ }^{38}$ M. GRAETZ, Les Juifs en France au XIXième siècle: De la Révolution Française à l'Alliance Israélite Universelle (París: Seuil, 1989; 1ª ed., Jerusalén: Bialik Institute, 1982) pág. 179.

39 TALmon Political Messianism pág. 79.

40 Graetz Les Juifs en France pág. 167. 
Israël n'a pas été crée et ne vit pas pour elle-même seulement. Peuple modèle, il lui incombe la tâche de montrer la voie de la redemption à l'humanité toute entière ${ }^{41}$.

La fusión religiosa sería -tal era la visión de los jóvenes sansimonianos- la forma final del mesianismo profético judío. En su Lettre à une Juive publicada en L'Organizateur (26 mar. 1831) Isaac Péreire escribía:

Si tu admets que la parole de Dieu ne s'applique pas à toutes les époques, et qu'elle subit des transformations [...] quelle motif aurais-tu pour repousser le Saint-Simonisme, qui n'est que le Mosaïsme perfectionné? ${ }^{42}$.

\section{LA CARRera FinANCIERA DE los PÉREIRE}

El sansimonianismo reforzó el espíritu de empresa, contribuyendo por lo tanto al desarrollo económico de Francia. No es cuestión de ocuparse aquí de la obra financiera de los Péreire, sino de investigar hasta qué punto su comportamiento reflejaba los valores que los Péreire habían absorbido del legado sefardí. Sin embargo, se impone un resumen breve de su carrera.

Tras unos años viviendo en París los Péreire empezaron a dar publicidad a su idea de atraer los ahorros populares a una caja de inversión que a su vez desarrollara obras públicas respaldada por el crédito oficial ${ }^{43}$. Insistieron en que el tipo de interés debería caer, mejorando así las condiciones de vida de la clase obrera:

Le petit commerce [...] pourrait participer plus largement alors aux avantages de crédit [...] Cette réduction de l'escompte [...] amènerait une baisse d'intérêt [...] et contribuerait ainsi à l'amélioration du sort des travailleurs ${ }^{44}$.

La preocupación de los Péreire por el reparto de la prosperidad quedaba siempre de manifiesto y así la expresaba Isaac Péreire:

Le signe auquel vous reconnaîtrez qu'une institution financière est bonne, c'est lorsqu'elle aura pour effet d'augmenter les salaires des travailleurs et de diminuer les revenues des oisifs ${ }^{45}$.

${ }^{41}$ Citado por Graetz Les Juifs en France pág. 23.

${ }^{42}$ Citado por Graetz Les Juifs en France pág. 160.

43 Autin Les Frères Péreire págs. 39-43; CAMERON France págs. 114-117.

${ }^{44}$ Citado por D. Cohen, La Promotion des Juifs en France à l'époque du Second Empire (Aix-en-Provence: Université de Provence, 1980) pág. 446.

45 COHEN La Promotion pág. 446. 
La prosperidad no era, sin embargo, meramente una cuestión de empobrecer a los ricos:

[...] c'est encore lorsqu'elle aura pour but d'accroître la richesse des premiers, bien que celle des seconds augmente aussi ${ }^{46}$.

No era cuestión de dinero, sino de una forma ilustrada de capitalismo cooperativo:

C'est enfin lorsqu'elle rendra plus rapide et plus économique le passage des instruments de travail dans les mains des producteurs et qu'elle leur en donnera une disposition plus complète ${ }^{47}$.

En 1842, habiendo terminado la construcción de los ferrocarriles París-Saint Germain y París-Versalles, los Péreire con los Rothschild establecieron la Compagnie du Chemin de Fer du Nord ${ }^{48}$. Antes de que la línea se completara, los Rothschild, siempre más conservadores y menos aventureros que los Péreire, retiraron su apoyo ${ }^{49}$. El futuro emperador Napoleón III, que dominaría Francia desde diciembre de 1851, participaba de ideas semejantes a las de Saint-Simon sobre el desarrollo industrial y del ferrocarril, y sobre el crédito barato, las cuales exigían la creación de instituciones financieras que desempeñasen papeles nuevos en la economía. Personajes indicados para llevar a la práctica tal visión eran los hermanos Péreire, cuya competencia técnica en el mundo de las finanzas se juntaba con un idealismo sansimoniano no compartido por los Rothschild.

Consecuencia de ello fue el Crédit Mobilier, gran caja de ahorros, empresa de holding autorizada el 18 de noviembre de 1852, que ofrecía crédito a cambio de deuda fácilmente negociable. En el fondo el Crédit Mobilier era un banco de inversión que financiaba las empresas industriales ayudándolas a acumular capital. La inspiración sansimoniana resultaba clara en las palabras pronunciadas por Isaac Péreire ante la asamblea anual de accionistas de 1854. El objetivo del banco era el de

46 Cohen La Promotion pág. 446.

47 Cohen La Promotion pág. 446.

${ }^{48}$ Los detalles de la carrera financiera e industrial de los Péreire se toman de Autin Les Frères Péreire.

49 Vid. J. Bouvier, Les Rothschild (París: Club Français du Livre, 1960) pág. 146. 
Amener sur le marché le concours régulier de capitaux nouveaux destinés à aider au développement du crédit et au crédit industriel ${ }^{50}$.

Para tal finalidad era necesario

Un nouvel agent ... faisant fructifier les épargnes des plus humbles ... ${ }^{51}$.

El Crédit Mobilier emitió 60 millones de francos de deuda en 120.000 acciones de quinientos francos cada una destinadas a atraer la atención de los que buscaban invertir sus modestos ahorros. Las acciones subieron pronto hasta 2.110 francos, de modo que algunas personas cuadruplicaron el valor de sus inversiones. Entre 1853 y 1866 la cotización variaba entre 640 y 960 francos. Tal avalancha de fondos permitió a los Péreire construir la línea BurdeosBayona y la de Burdeos a Cette.

Durante la década de los 1850 estaban en vías de construcción $14.260 \mathrm{kms}$. de ferrocarriles franceses, en gran parte debido a la iniciativa de los dos hermanos oriundos de la comunidad portuguesa de Burdeos. Para 1858, los Péreire se interesaban también por los seguros e invertían en el extranjero. Precisamente en España, tierra de sus lejanos antepasados, lo hacían en minas, en la compañía de gas de Madrid, y en seguros, creando La Unión y el Fénix Español.

Subdesarrollada como estaba, España ofrecía un rico campo especialmente para la construcción de ferrocarriles. Un gobierno liberal había permitido el establecimiento de cuatro bancos extranjeros de inversión ${ }^{52}$, entre ellos el Crédito Mobiliario Español con 240.000 acciones. Los Péreire obtuvieron la concesión para la construcción de la línea ferroviaria entre la frontera francesa y Madrid 53

El Crédito Mobiliario Español invertía en fábricas, azucareras, industrias de cerámica, instalaciones portuarias, almacenes y fincas urbanas. En esa época llegaron a Madrid y a Barcelona algunos judíos ingenieros y otros especialistas, lo cual llevó al periódico

50 GRAETZ Les Juifs en France pág. 211.

${ }^{51}$ GRAETZ Les Juifs en France pág. 211.

52 Gaceta de los Caminos de Hierro 1 (27 abril 1856).

${ }^{3}$ Gaceta de los Caminos de Hierro 3 (11 mayo 1856). Los Rothschild financieron la otra gran línea española, la de Madrid - Zaragoza - Alicante, siguiendo además su papel tradicional de organizar préstamos para el Estado por medio de sus agentes Weisweiller y Bauer. 
judío francés $L$ 'Univers a vaticinar la supresión del decreto de expulsión de $1492{ }^{54}$. Se equivocaba; no había que subestimar la fuerza del tradicionalismo español.

Los Péreire llevaron a Italia, a Holanda y a Turquía su capacidad para aunar la ingeniería civil, la eficacia administrativa y la técnica bancaria. Consigo llevaron las ideas sansimonianas de desarrollo y de espíritu de empresa. Conducían las finanzas de dieciséis firmas con un capital acumulado que equivalía a la quinta parte de todos los valores comercializados en la Bolsa de París ${ }^{55}$ y figuraban como socios delegados de muchas más empresas.

La depresión de 1857 marcó el comienzo de la caída de los Péreire, los cuales se vieron obligados a liquidar sus inversiones en ferrocarriles. Una serie de grandes escándalos financieros que no afectaron directamente a los Péreire inclinaron sin embargo a Napoleón III a favorecer a los menos especuladores Rothschild.

Los Péreire participaban intensamente en la bonanza inmobiliaria de los años 60 en París, en Burdeos, su ciudad natal, y en Marsella. Pero al declinar el prestigio del Segundo Imperio los Péreire se fueron encontrando en dificultades financieras, precisamente al ir cayendo los valores inmobiliarios. El siempre hostil Banco de Francia se negó a descontar su papel. Como resultado y para salvar algunas de sus empresas, los hermanos tuvieron que abandonar en 1867 el consejo administrativo del Crédit Mobilier ${ }^{56}$.

\section{VIDA PERSONAL DE LOS PÉREIRE}

Los Péreire se casaron con mujeres judías e incluso sefardíes, y asistían a la sinagoga en los principales días santos, pero se mantuvieron alejados de la organización comunitaria judía. Aunque estaban completamente integrados en el mundo francés, no se separaron de la comunidad judía, contribuyendo liberalmente a la construcción de templos y a obras caritativas. Incluso el consistorio de París sacó altas ganancias de las acciones del Crédit Mobilier donadas por los Péreire ${ }^{57}$.

\footnotetext{
${ }^{54}$ GRAeTZ Les Juifs en France pág. 78.

55 CARlisle The Proffered Crown pág. 6.

${ }^{56}$ Para detalles acerca de las finanzas y de las diversas caídas de las empresas vid. L. GIRARD, La politique des travaux publics du Second Empire (París: Armand Colin, 1952) págs. 109ss.

57 GraETZ Les Juifs en France pág. 141.
} 
Sin seguir las normas del judaísmo tradicional, los Péreire proclamaban su lealtad a los valores judíos mientras estos fueran demostrablemente sansimonianos. La tarea de la religión para ellos era moral: asegurar la felicidad humana. Así lo expresaba el veinteañero Emile en una carta a su tío:

Je ne suis pas religieux, tu sais. Je suis né dans la religion israélite, j'y demeure [...] Je souhaite et j'espère de voir diminuer l'importance des idées religieuses, parce qu'au point douteux où elles sont parvenues, elles gênent le libre arbitre et entretiennent une dissimulation constante dont personne n'est dupe mais dont chacun a à souffrir ${ }^{58}$.

Las opiniones de los hermanos cambiaron poco. En 1869, cuando en una campaña electoral se atacaba a Isaac por judío, el periódico Archives Israélites escribía que «[...] né israélite mais nous pouvons dire [...] qu'il tient peu à cette qualification» ${ }^{59}$.

El ideal de los Péreire era el bienestar humano. Cuando en 1876 Isaac compró el periódico La Liberté puso en la cabecera el mismo lema sansimoniano que había ostentado Le Globe, donde cuarenta y cinco años antes habían aparecido los primeros textos de Emile:

Toutes les institutions doivent avoir pour but l'amélioration morale, intellectuelle et physique de la classe la plus nombreuse et la plus pauvre ${ }^{60}$.

En su vejez Isaac Péreire reunió una serie de textos en un pequeño tomo llamado La question religieuse et sociale. En él declaraba que la Iglesia seguía sin hacer frente a la crisis social y moral de la humanidad; la manera de vencer la pobreza era aunando el poder laico con la ciencia y la industrialización. Pero así como la Revolución se equivocaba por ser anticlerical, la Iglesia temía el progreso sin motivo ${ }^{61}$.

A sus setenta años Isaac identificaba la política con la religión bíblica. Ni el deísmo ni el racionalismo, insistía, ofrecían una solución, la cual podría hallarse únicamente en la visión sansimoniana

${ }^{58}$ Citado por Autin Les Frères Péreire pág. 331.

59 Citado por COHEn La Promotion pág. 596.

${ }^{60}$ Citado por COHEN La Promotion pág. 455.

${ }^{61}$ Hemos consultado este libro en su traducción inglesa (Londres 1879); vid. págs. $3,5,17,19$ y 50-51, así como el cap. X passim. 
de la mejora de la suerte de la gran mayoría por medio de la enseñanza, la organización del factor trabajo y la introducción de las prestaciones sociales, distribuyendo más justamente la riqueza y aumentando la producción. Como, según el concepto sansimoniano, todos y cada uno tienen una aptitud determinada, la división del trabajo debería fundamentarse en aquella aptitud y en el crédito hábilmente dirigido en una sociedad donde el principio de mutualidad representaba el ideal.

Efectivamente, como patronos los Péreire respetaron sus propios principios. Pagaban buenos sueldos, dando a sus empleados un mes extra de sueldo cada año; introdujeron programas de reparto de beneficios, seguros de vida y contra accidentes de trabajo, socorrían a las familias de los empleados fallecidos y ofrecían tratamiento médico gratuito. A su muerte Emile legó cincuenta mil francos a los pobres ${ }^{62}$.

Después de la guerra contra Prusia de 1870-1871, los hermanos fueron abandonando sus intereses comerciales. Emile murió en 1875 e Isaac vivió cinco años más, dirigiendo el periódico La Liberté. En su estudio en la casa de los Péreire en la Rue St. Honoré, se encontraba un busto y, escondido, el cráneo de Henri de Saint-Simon.

\section{CONCLUSIÓN}

Las declaraciones repetidamente hechas por los Péreire durante su vida junto con su comportamiento como financieros y como patronos subrayan la importancia que tuvo para ellos el sansimonianismo. Hemos querido demostrar que este movimiento tuvo también cierta repercusión en mentes judías, sobre todo en aquellas que se habían criado en las tradiciones judeo-portuguesas y habían sido testigos de los sucesos recientes ocurridos entre los ex-cristianos nuevos de Burdeos, los cuales habían puesto de relieve su visión racionalista y ética.

Tal insistencia en una moralidad basada en el bienestar material humano, hostil a la idea estática de economía y sociedad idealizada por la Iglesia, parece particularmente judía. En sus escritos de 1831 para Le Globe Emile Péreire lo explica desde los aspectos

62 Autin Les Frères Péreire págs. 323-324. 
históricos y sociológicos. Los judíos eran los que poseían bienes móviles y dinero líquido, por lo cual eran ellos los que habían inventado la letra de cambio, raíz del sistema crediticio.

Los escritos de los Péreire no vinculan sus ideas de modo explícito con las enseñanzas judías. Sin embargo, tales ideas tienen una relación evidente con la obligación judía de «ticún 'olam», concepto según el cual los seres humanos actúan como co-trabajadores del ser divino en la tarea de perfeccionar el mundo en el sentido material además del espiritual. Dado lo que se sabe del ambiente en las comunidades oriundas de los cristianos nuevos de la Península Ibérica a través de los escritos del rabino Azulay y del Régistre de la comunidad de Burdeos, sumado al ambiente de la Ilustración, de la Revolución francesa y del modelo impuesto por Napoleón Bonaparte -modelo del cual los jefes de la comunidad sefardí se esforzaban por mostrarse como paradigmas-, puede concluirse que la educación de los Péreire, realizada en un ambiente que hubo de inclinarles hacia cierta síntesis religiosa dentro de un marco moral, tiene sus raíces en las exigencias morales de los profetas bíblicos.

Ahora bien, para los Péreire tal espíritu sefardí y sansimoniano era más que un deísmo impreciso. Emile lo dijo claramente al pronunciar una conferencia en el Ateneo sansimoniano publicada en Le Globe (16 sep. 1831):

La religion n'est plus pour nous ce lien vague et mystique qui attache l'individu à un dieu pur esprit, cherche à le séparer du monde et lui fait envisager la magnifence et la beauté que la nature déploie incessament devant lui... Ah! Nous avons une notion bien plus élevée de Dieu et de la religion. Dieu vit aussi dans la matière, car tout est lui [cursiva mía]. C'est la manifestation matérielle de Dieu lui-même qui par l'industrie est embellie. La religion est ce qui lie les hommes entre eux et avec le monde extérieure; or, tout progrès vers l'association, tout progrès dans l'explotation du globe terrestre est un progrès éminemment religieux.

El que «todo es Dios», según hemos destacado en el texto de Emile Péreire, era la opinión de Spinoza, el filósofo de Amsterdam descendiente de cristianos nuevos, condenado por los rabinos en el siglo XVII por negar una identidad a Dios separada de la naturaleza. Este punto de vista es lo contrario del concepto deísta de la naturaleza o de la materia como entidades separadas de la figura divina transcendente y remota. Sin embargo, si se hubiera exigido a Emile 
Péreire examinarse de opiniones teólogicas, probablemente no hubiera insistido en la identificación de Dios con la materia, sino que hubiera explicado que Dios se manifiesta en el desarrollo y la mejora, no sólo en los aspectos espirituales de la vida sino también en los aspectos materiales, y que lo terrenal comporta lo espiritual. Esta idea era la que sostuvo a los Péreire durante toda su vida.

\section{RESUMEN}

Los hermanos Emile e Isaac Péreire nacieron al principio del siglo XIX en la comunidad judeo-portuguesa de Burdeos en una época en que los judíos de Francia avanzaban hacia la plena integración en la sociedad civil. Los Péreire eran herederos de una educación sefardí que se limitaba a aquellos aspectos de la tradición y la religión judías compatibles con las ideas de la Ilustración. Por consiguiente, los Péreire encontraron un eco de su visión íntima en el sansimonianismo, cuyos principios mantuvieron durante toda su vida, dedicada al progreso industrial a base del enriquecimiento del pequeño inversor.

\section{SUMMARY}

The brothers Emile and Isaac Pereire were born at the beginning of the 19th century in the Spanish and Portuguese Jewish community of Bordeaux, at a time when French Jews were moving towards full integration with society. They had been brought up in a Sephardi educational tradition reformed in the context of the Enlightenment. Consequently, they found their own views reflected in the Saint-Simonian movement and subscribed to its principles throughout their career, which they devoted to industrial progress on the basis of the prosperity of the small saver. 